\title{
Congenital anomalies of the male urethra
}

\author{
Terry L. Levin • Bokyung Han • Brent P. Little
}

Received: 27 December 2006/Revised: 15 March 2007 / Accepted: 6 April 2007 / Published online: 22 May 2007

(C) Springer-Verlag 2007

\begin{abstract}
The spectrum of congenital anomalies of the male urethra is presented. The embryologic basis of each anomaly, when known, is discussed. Clinical and imaging features of each entity are presented.
\end{abstract}

Keywords Male urethra - Anomalies · Embryology Congenital

\section{Introduction}

The development of the male genitourinary system is complex. Numerous anomalies of the male urethra exist, either as isolated anomalies or in combination with other disorders. The current understanding of the embryology and anatomy of normal male urethral development might help explain the causes of the various anomalies as well as their relationships.

\section{Embryology of the male urethra}

Between weeks four and five of fetal life, the cloaca is separated from the amniotic cavity by the cloacal membrane [1]. The cloaca is divided into the urogenital sinus and the hindgut by the urorectal septum, which descends in a rostral-to-caudal fashion (Fig. 1). The urogenital sinus is the precursor of the bladder and posterior urethra. The urorectal septum is formed by proliferation, migration and

T. L. Levin $(\bowtie) \cdot$ B. Han • B. P. Little

Department of Radiology,

Children's Hospital at Montefiore Medical Center,

714 Forest Ave,

Mamaroneck, NY 10543, USA

e-mail: jebl1@optonline.net fusion of mesodermal folds that arise from the lateral walls of the cloaca. When the urorectal septum reaches the caudal aspect of the cloaca, the cloacal folds, which lie on the dorsal portion of the cloacal membrane, fuse to form the rudimentary perineum. The cloacal membrane subsequently undergoes disruption such that the hindgut and phallic cloaca open separately to the exterior, divided by the urorectal septum (Fig. 2).

The most caudal aspect of the cloaca (phallic cloaca) extends distally through the developing genital tubercle. Proliferation of rostral mesoderm of the genital tubercle displaces the cloaca so that it lies on the caudal aspect of the developing glans (Fig. 3). Failure of this step results in epispadias. The endodermal lining of the phallic cloaca appose to form the urethral plate. Portions of the cloacal membrane also contribute to the urethral plate (Fig. 4). The urethral plate undergoes median cleavage. Following mesodermal proliferation and fold fusion extending proximally to distally, the shaft urethra and proximal two-thirds of the glandular urethra are formed. This is lined by endoderm. The distal urethra at the glans penis is formed from fusion of distal folds that arise from the apical part of the glans distal to the cloaca and subsequent urethral plate (Fig. 4). It is lined by ectoderm [2-4]. Discontinuity in the urethral plate or abnormality of fusion of the urethral folds can lead to hypospadias.

\section{Normal anatomy of the male urethra}

The male urethra is divided into the prostatic, membranous and penile (cavernous) urethra (Figs. 5 and 6). The prostatic urethra courses through the prostate and is the widest part of the urethra. On the posterior wall of the prostatic urethra lies the urethral crest, an elevated longitudinal ridge of 


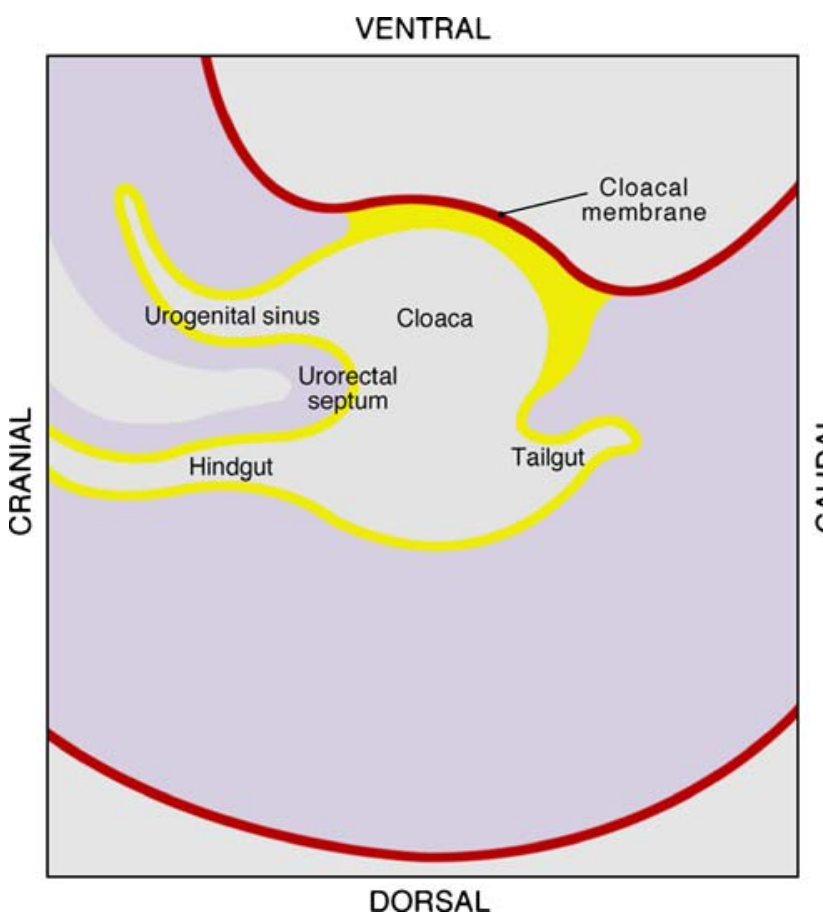

Fig. 1 Embryologic development of the male genitourinary tract. The cloaca is divided into the urogenital sinus (precursor of the bladder and posterior urethra) and the hindgut by the urorectal septum (adapted from reference 2)

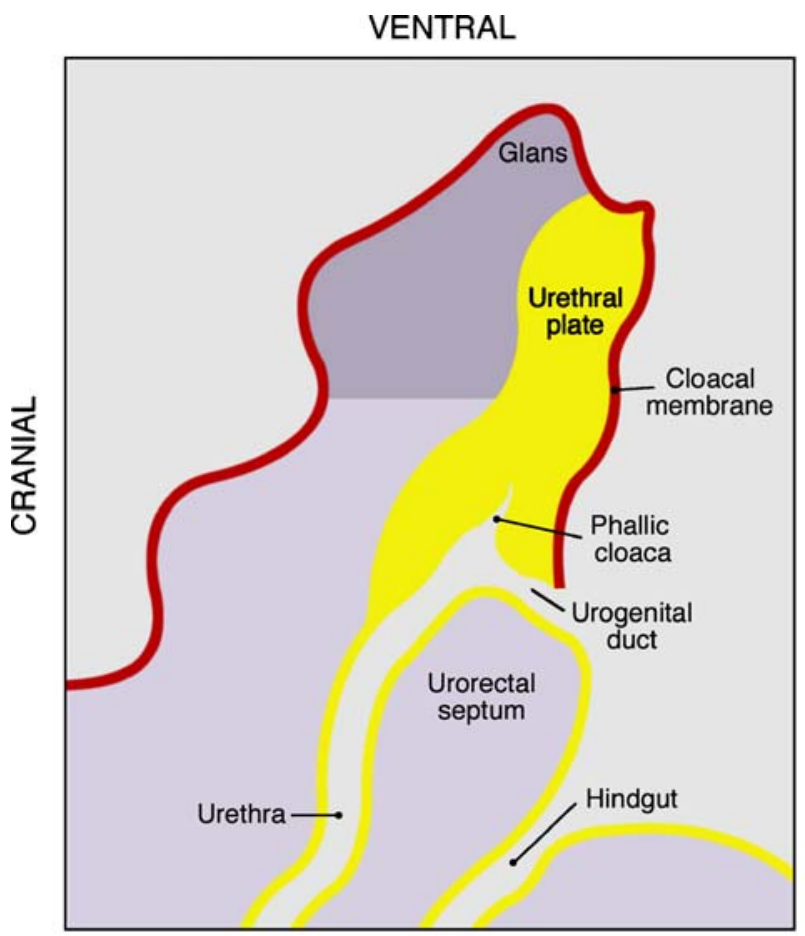

DORSAL

Fig. 2 Embryologic development of the male genitourinary tract. The urorectal septum continues to descend and the cloacal membrane undergoes disruption. The hindgut and phallic cloaca now open separately to the exterior (adapted from reference 4)

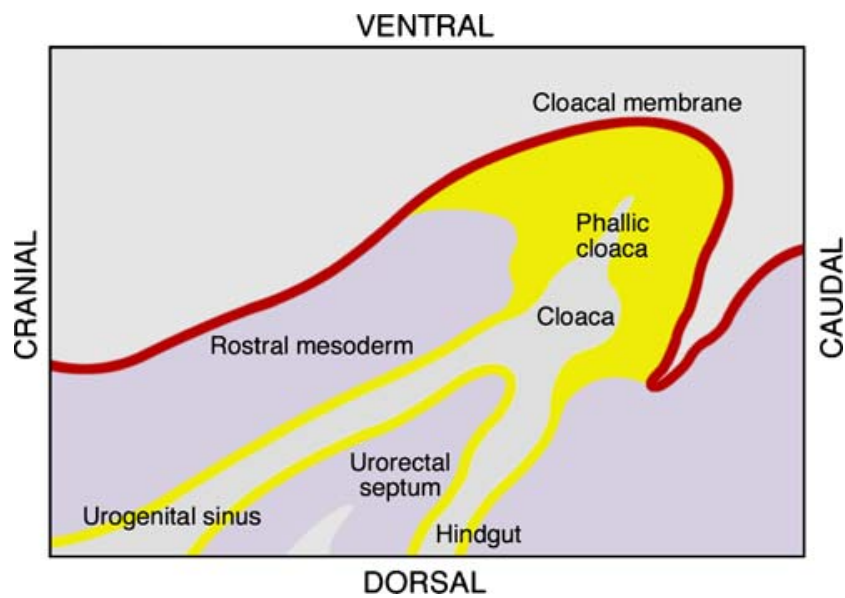

Fig. 3 Embryologic development of the male genitourinary tract. The phallic cloaca extends distally through the developing genital tubercle. Proliferation of rostral mesoderm of the genital tubercle displaces the cloaca so that it lies on the caudal aspect of the developing glans (adapted from reference 2)

tissue. The verumontanum (seminal colliculus) is located at the midportion of the urethral crest and is the site of the ejaculatory duct orifices. Additionally, the orifice of the prostatic utricle, a glandular grouping, is located at the summit of the verumontanum. The utricle, a derivative of the Mullerian duct and urogenital sinus, and the male homologue of the uterus and vagina, is a blind indentation that extends dorsally into the prostate and can measure up to $6 \mathrm{~mm}$. The prostatic ducts drain into the prostatic sinus, the fossa on either side of the elevated urethral crest. The intermuscular incisura produces an indentation on the anterior aspect of the prostatic urethra, at the level of the verumontanum, and results from prominent collagenous tissue.

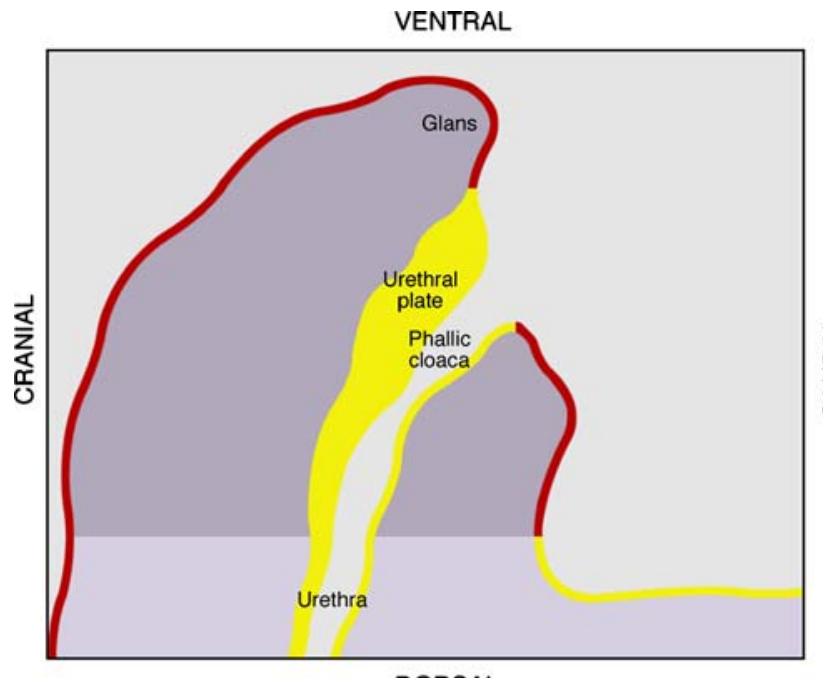

Fig. 4 Embryologic development of the male genitourinary tract. Median cleavage of the urethral plate occurs. The urethral plate forms the deep and lateral walls of the proximal urethra. The phallic cloaca opens to the exterior at the base of the glans (adapted from reference 4) 


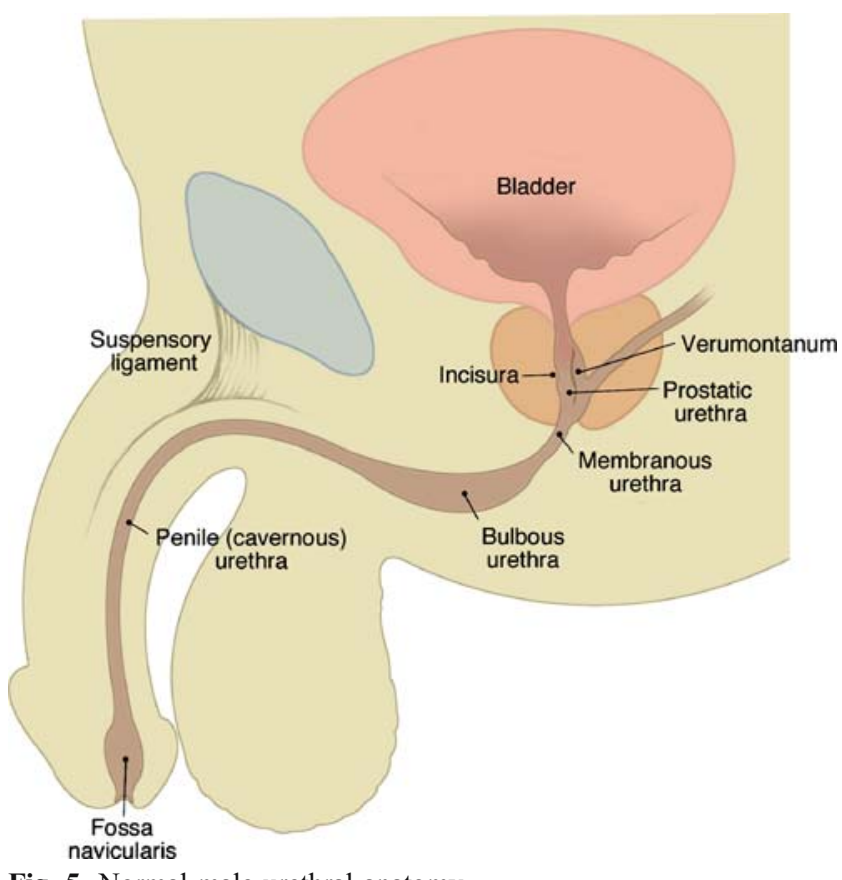

Fig. 5 Normal male urethral anatomy

The membranous urethra is the shortest, least distensible portion of the urethra. It is surrounded by the sphincter urethrae membranaceae (external sphincter), which in addition to vessels, nerves and deep transverse perineal muscle represents the urogenital diaphragm. The internal sphincter is located at the bladder neck.

The penile urethra is the longest portion of the urethra. The proximal portion of the penile urethra, the bulbar urethra, is dilated and is the site of drainage of Cowper's ducts. The penile urethra is also dilated distally at the glans penis, where it forms the fossa navicularis. The midportion of the penile urethra is tethered superiorly by the suspensory ligament [5].

\section{Congenital anomalies of the urethra}

Posterior urethral valves

Posterior urethral valves (PUV), first described in 1717 by Morgagni, occur in one of every 5,000-8,000 male infants [6]. PUV can lead to bilateral renal obstruction, bladder dysfunction, vesicoureteral reflux, hydronephrosis and renal damage. In 1919, Young proposed a classification system consisting of three types of valves. Type I valves (the most common) arise from the verumontanum and extend distally to attach to the lateral walls of the urethra as two leaflets (type Ia) or as a unicuspid leaflet (type Ib). Type II valves extend proximally from the verumontanum to the bladder neck, and type III valves represent a diaphragm attached to the circumference of the urethra with a central hole, distal (type IIIa) or proximal (type IIIb) to the verumontanum [1, 8]. The existence of Young's type II valves is debated [7]. Type III valves are considered by many to be the same entity as Cobb's collar and are discussed in the section on congenital urethral strictures $[1,7]$.

The valves are composed of connective tissue interspersed with smooth muscle, similar to the tissue encasing the ejaculatory ducts, and are lined by stratified squamous epithelium rather than the transitional epithelium that lines the posterior urethra [1].

The embryologic defect leading to the development of PUV is not known. Many authors believe the anomaly is caused by abnormal integration of the Wolffian ducts into the urethra, while others consider it a result of persistence of the cloacal membrane $[1,7]$.

Autopsy studies have shown that the valves represent a single obliquely oriented diaphragm rather than a bicuspid structure as originally believed $[7,9]$. The term congenital obstructive posterior urethral membrane (COPUM) has, therefore, been introduced [10].

Many cases of PUV are detected by prenatal sonography. Normal fetal renal parenchyma and amniotic volume do not necessarily predict good postnatal renal function [11]. Intrauterine intervention, while improving hydronephrosis, does not prevent the development of renal dysplasia [12]. Newborns might present with pulmonary hypoplasia secondary to oligohydramnios, or an abdominal mass caused by hydronephrosis or bladder distension. In older patients clinical signs include failure to thrive, poor urinary stream, sepsis, poor renal function or salt-losing nephropathy [13].

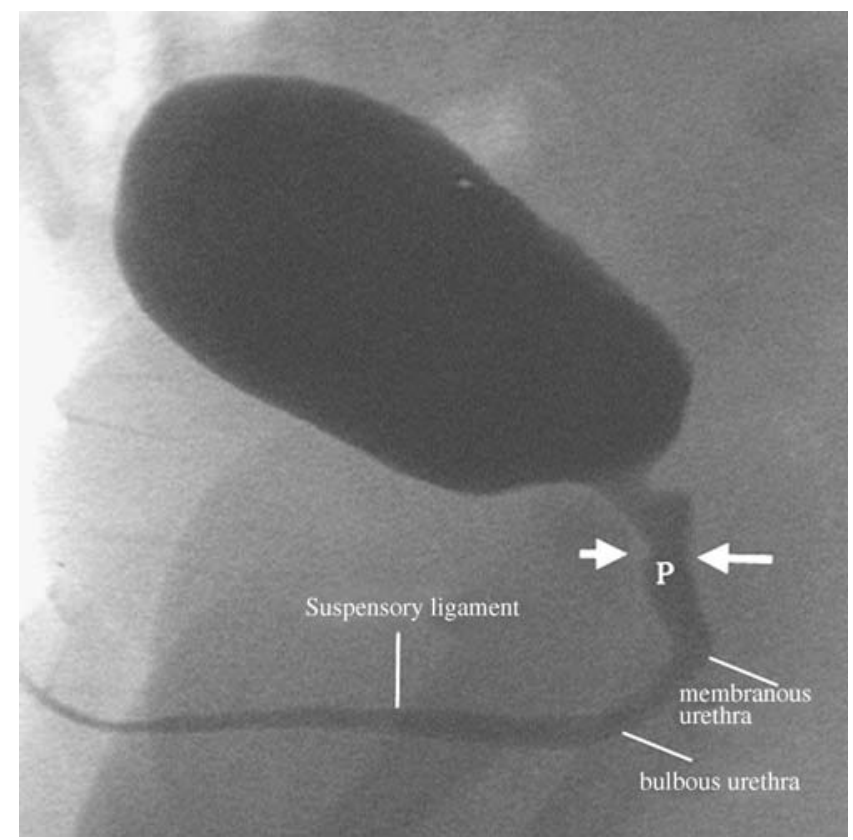

Fig. 6 Voiding cystogram in a 3-year-old with prior urinary tract infection. Normal urethral anatomy is shown $(P$ prostatic urethra, short arrow incisura, long arrow verumontanum) 


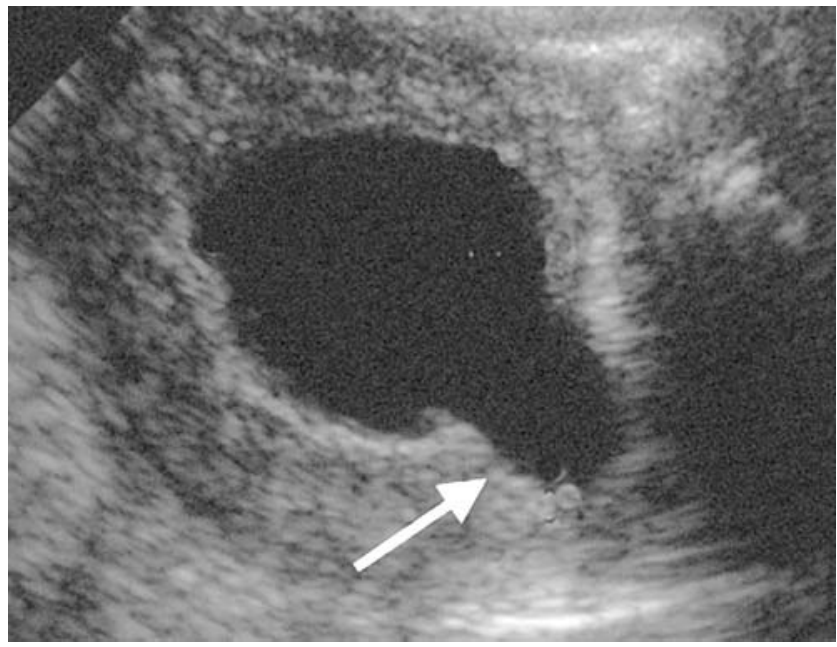

Fig. 7 Posterior urethral valves. Sonography demonstrates a thickwalled bladder and dilatation of the prostatic urethra (arrow), the "keyhole sign"

Treatment is by fulguration of the valve, although in infants vesicostomy or pyeloureterostomy might be performed prior to valve ablation. Posterior urethral dilatation persists after fulguration in $20 \%$ of patients. Despite therapy, $40 \%$ of patients have poor renal growth and another $40 \%$ develop end-stage renal disease $[12,14]$. A normal or near normal serum creatinine level or GFR at 1 year of life, following decompression of the urinary tract, are useful positive prognostic indicators $[12,14]$. In contrast, the development of proteinuria is associated with a poor prognosis [14].

Ultrasonography is usually the initial imaging modality used to evaluate patients with suspected PUVs. US reveals a

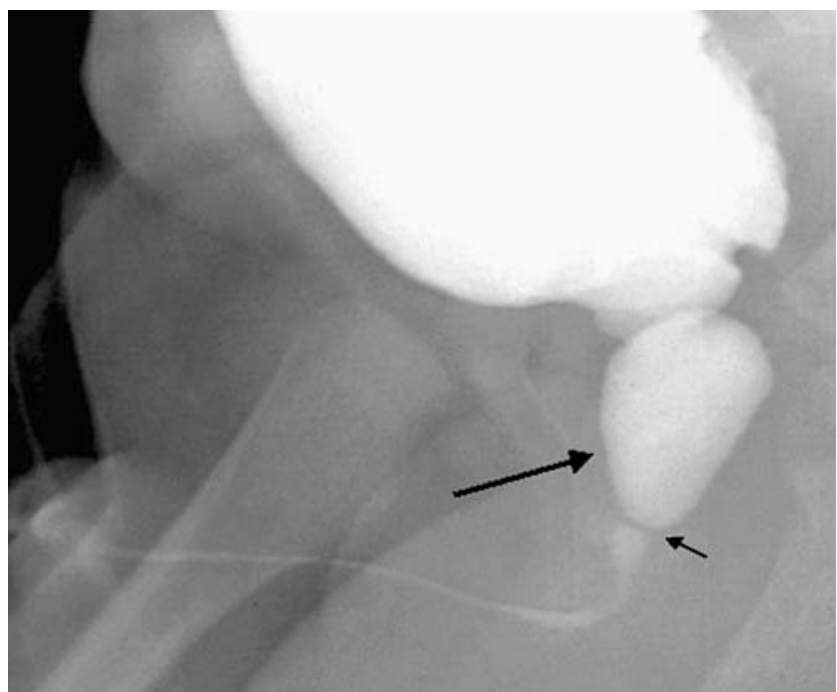

Fig. 8 Posterior urethral valves. An image from a VCUG demonstrates a thick-walled trabeculated bladder and dilatation of the posterior urethra (long arrow), and the location of the valve (small arrow)
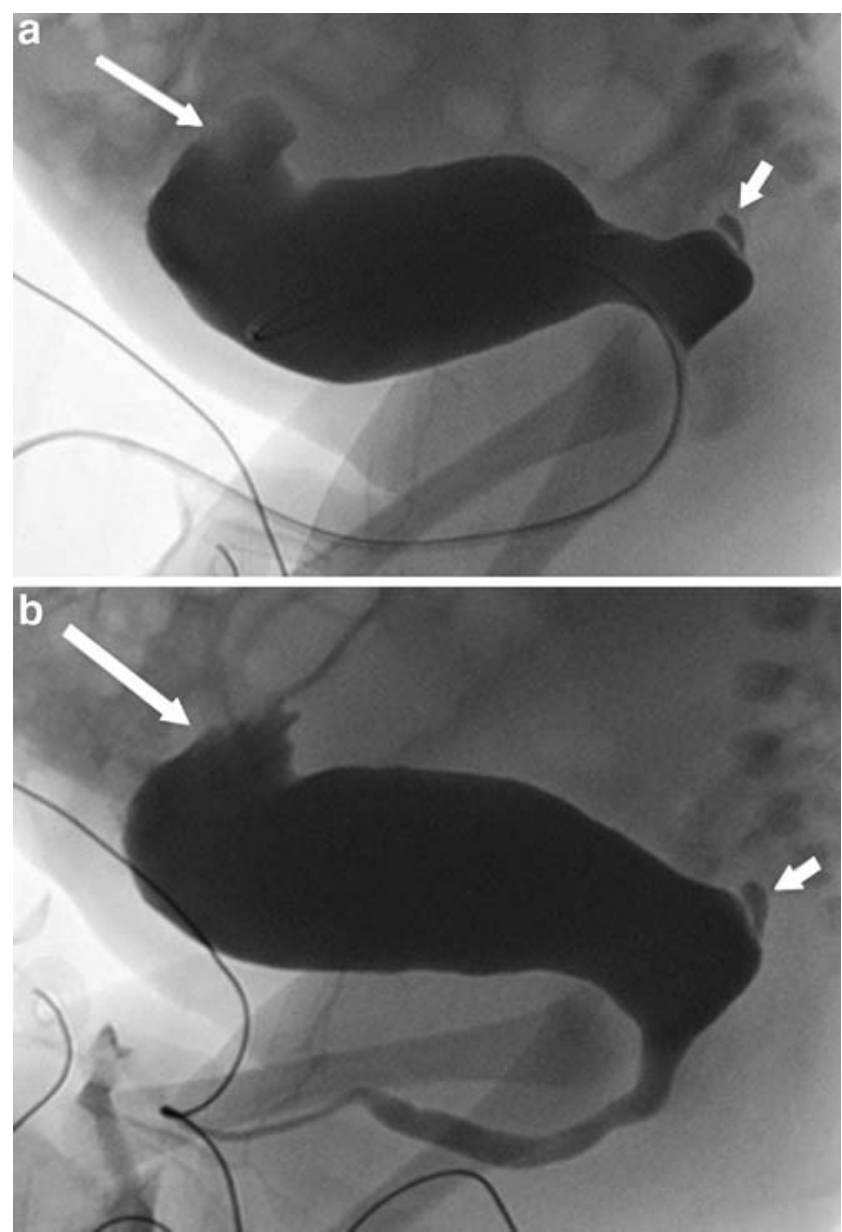

Fig. 9 Prune-belly syndrome. a Images from a VCUG show the characteristic smooth-walled bladder that is tethered anteriorly by a urachal remnant (long arrow). Note the utricle (short arrow) arising from the dilated prostatic urethra, which is positioned dorsal to the wide bladder neck. b Voiding film shows dilatation of the proximal urethra consistent with megalourethra. Megalourethra can coexist in these patients

thick bladder wall and bilateral but asymmetric hydronephrosis. Transperineal sonography can demonstrate dilatation of the posterior urethra (the "keyhole" sign) (Fig. 7) [15]. A perirenal urinoma from forniceal rupture or urinary ascites can also be seen. PUV is the most common cause of urinary ascites in the newborn [16]. Echogenic kidneys might also be seen and are associated with a poor prognosis [14].

Typical findings of PUV on voiding cystourethrography (VCUG) include a trabeculated bladder with diverticula, dilatation of the prostatic urethra and a discrepancy between the caliber of the prostatic urethra and the bulbar and penile portions of the urethra (Fig. 8). During voiding, the contrast stream between the prostatic urethra and bulbous portion of the urethra is more dorsal in position than normal. Vesicoureteral reflux is present in $50 \%$ of cases and is more often unilateral than bilateral. Reflux into the prostate might also be seen. 


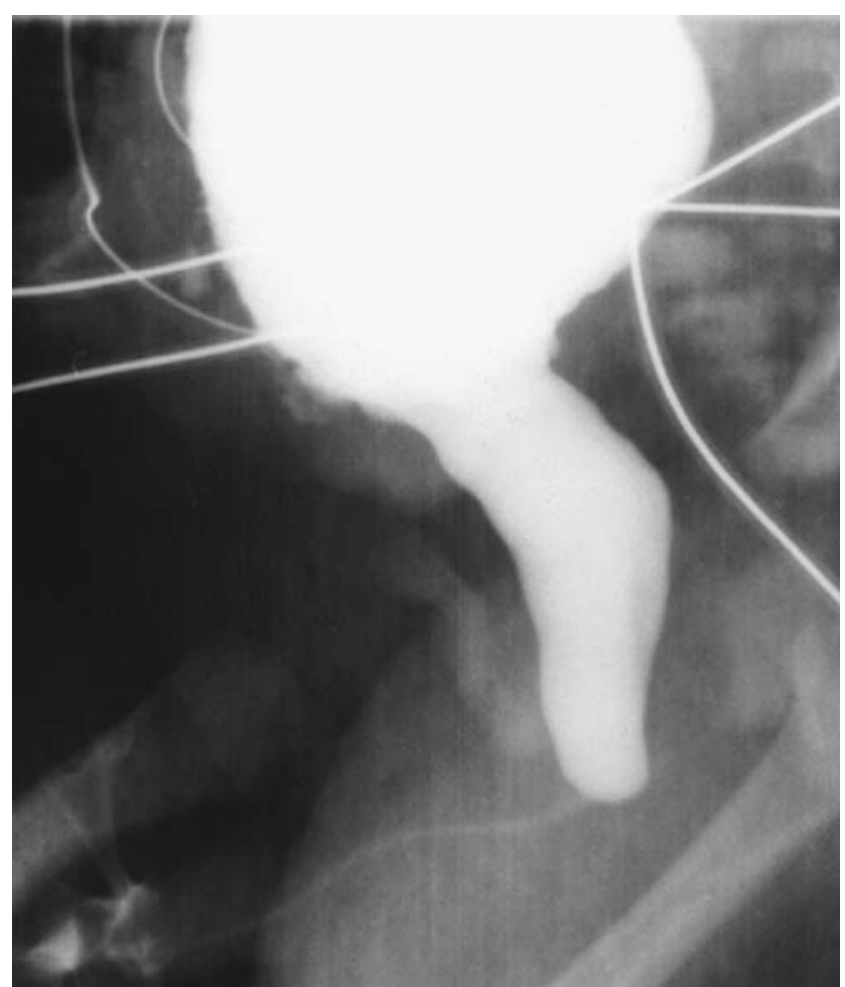

Fig. 10 Congenital urethral stricture. A markedly dilated urethra is seen proximal to a congenital stricture in the bulbous urethra. Retrograde urethrography in this patient (not shown) demonstrated a focal narrowing at the bulbous urethra with a normal penile urethra. The site of obstruction is more distal than that seen with PUV

\section{Prune-belly syndrome}

Prune-belly syndrome (PBS) was first described in 1950 by Eagle and Barret as a triad of deficient abdominal wall muscles, urinary tract anomalies and cryptorchidism. Associated abnormalities include cardiac, limb and intestinal abnormalities (30\% of patients have malrotation). Although PBS is primarily seen in males, it has been described in females; female patients have genital abnormalities including bicornuate uterus and vaginal atresia [17].

Urinary tract abnormalities, which can be evaluated by sonography and VCUG, include both upper tract disease and lower tract disease. Hydroureter, more pronounced than the coexisting hydronephrosis, is caused by poor ureteral peristalsis and poor bladder emptying rather than true obstruction. Varying degrees of renal dysplasia with or without cystic change might be present. Characteristic findings on VCUG include a large, smooth-walled bladder without trabeculations and marked bilateral vesicoureteral reflux into tortuous and laterally positioned ureters. A urachal diverticulum might be present, resulting in anterior and midline tethering of the bladder dome (Fig. 9). Calcification is rarely identified within the bladder and urachal diverticulum and is secondary to urinary stasis [18].
The prostatic urethra is dilated secondary to or in association with prostatic aplasia or hypoplasia. (Pathologically, the verumontanum is small and the ejaculatory ducts are normal.) Unlike PUVs, the prostatic urethra in patients with PBS is high in position and its posterior wall is elongated relative to its anterior wall. A normal utricle might be present. The penile urethra might be normal, or additional urethral anomalies such as megalourethra, urethral atresia or coexisting posterior urethral valves can be present. Patients with urethral obstruction do not survive [17].
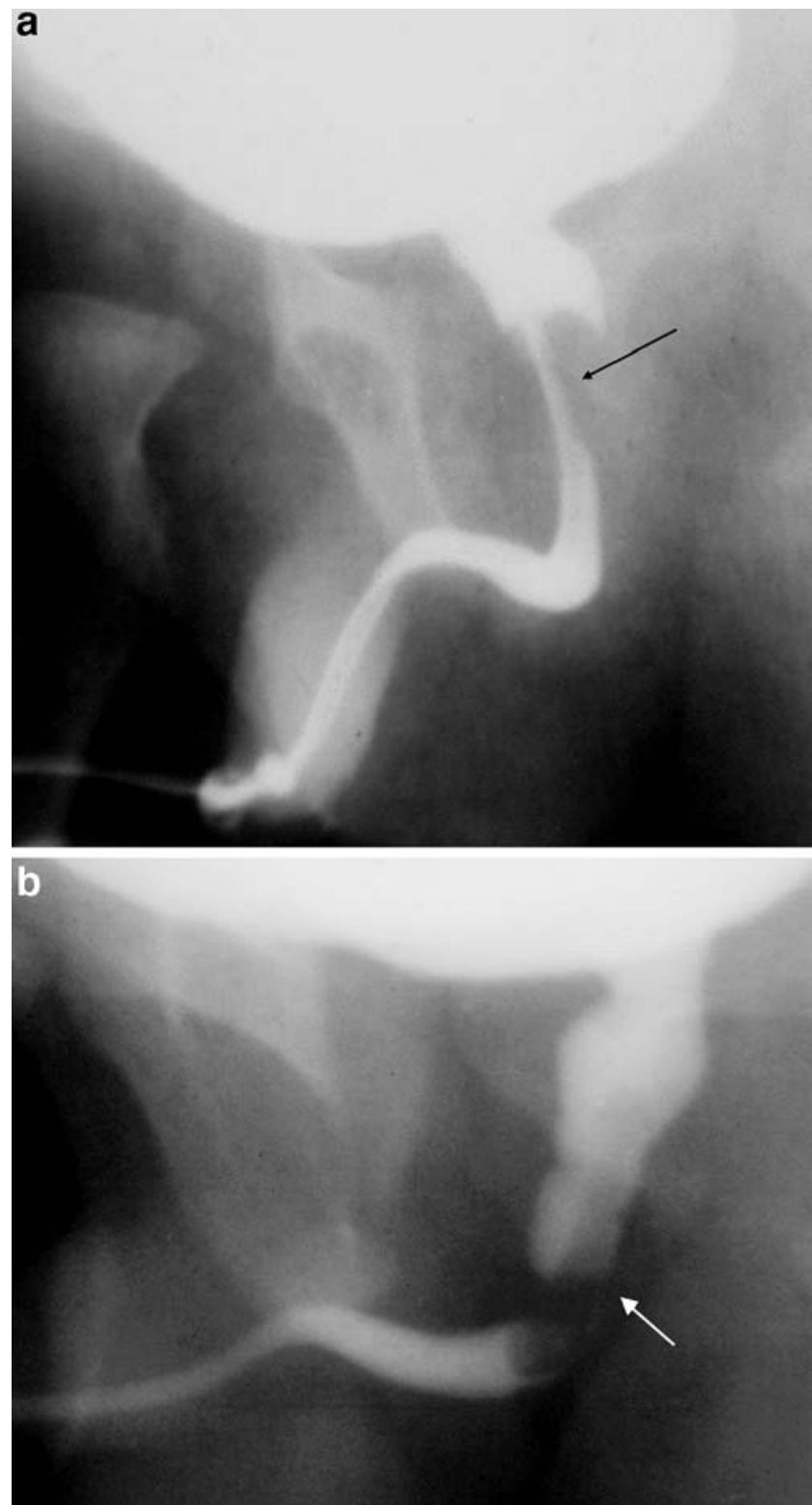

Fig. 11 Urethral polyp. a Image from a VCUG demonstrates a polypoid filling defect arising from the prostatic urethra (arrow). b Note change of position of the filling defect (arrow) during the examination (images courtesy of J. Michael Zerin, MD) 


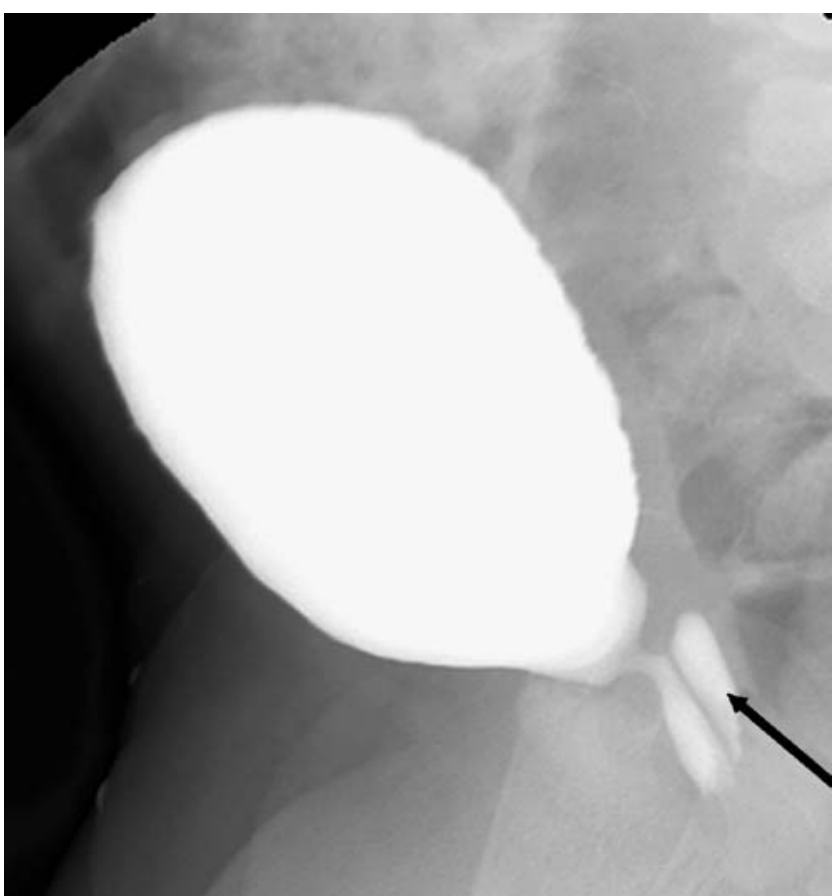

Fig. 12 Utricle. Voiding cystourethrogram in a child with urinary tract infection demonstrates a normal utricle that was incidentally detected (arrow). The ventral urethra is not filled with contrast material

\section{Congenital urethral stricture}

Although most urethral strictures in males are posttraumatic, there are rare reports of congenital urethral strictures of the bulbous urethra in neonates and older children [19]. These might be secondary to a failure of canalization of the cloacal membrane during fetal development $[1,20]$ and have also been referred to as Cobb's collar, Moormann's ring and Young's type III valve [7, 19]. Patients present with urinary tract infection. Older children might have diurnal enuresis. Diagnosis is by VCUG or retrograde urethrography. VCUG will demonstrate focal narrowing of the bulbous urethra, while retrograde urethrography will confirm a normal penile urethra. The site of urethral narrowing in congenital urethral stricture is distal to the external urethral sphincter, which differentiates this entity from PUV (Fig. 10). Vesicoureteral reflux can be seen in up to $53 \%$ of patients [20]. Treatment is by transurethral incision. Other causes of urethral stricture, including trauma, must be excluded.

\section{Congenital urethral polyps}

Congenital urethral polyps are benign and arise from the prostatic urethra near the verumontanum. They are composed of vascular connective tissue, although glandular and nerve tissue have been described. Because they have a stalk, these polyps are mobile and can move proximally into the bladder or distally into the bulbous urethra. They can be a cause of urethral obstruction or bleeding. VCUG is diagnostic and demonstrates a mobile filling defect in the bladder neck or below the verumontanum (Fig. 11). Endoscopic resection is the treatment of choice [21, 22].

Mullerian duct remnants: enlarged prostatic utricle and Mullerian duct cyst

The normal prostatic utricle (Latin for "pouch of the prostate") is a minute, blind opening located at the verumontanum [23, 24]. It is a glandular grouping lined with epithelial cells with differentiation similar to those lining the main prostatic ducts and acini [23]. It has no function and is the male homologue of the female uterus and vagina (Fig. 12).

Midline cystic structures arising at the dorsal aspect of the prostatic urethra represent two distinct categories of Mullerian duct remnants. They are described as enlarged prostatic utricles when they communicate with the urethra and as Mullerian duct cysts when they do not. These terms have been used interchangeably, contributing to confusion in nomenclature.

An enlarged prostatic utricle is a congenital abnormality. Although its embryogenesis is not certain, theories include

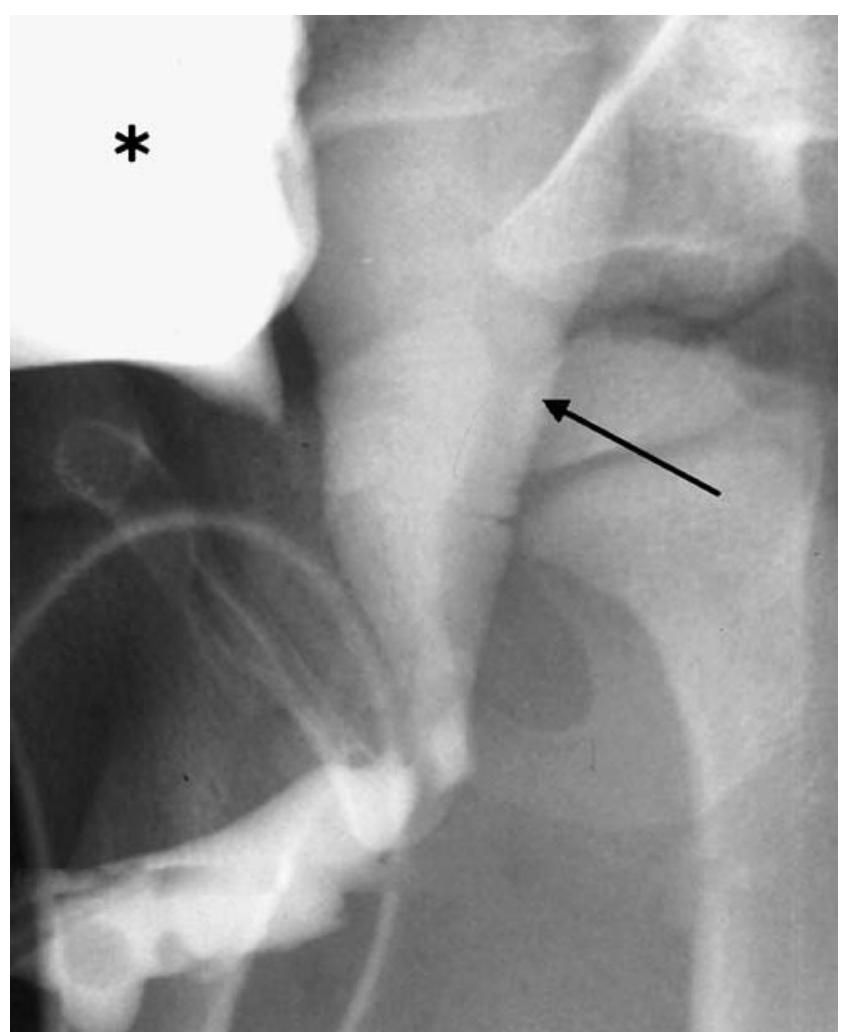

Fig. 13 Enlarged prostatic utricle. There is filling of a large utricle (arrow) that arises from and communicates with the posterior urethra in this patient with intersex abnormality. The patient has had penile urethral reconstruction (asterisk bladder) 


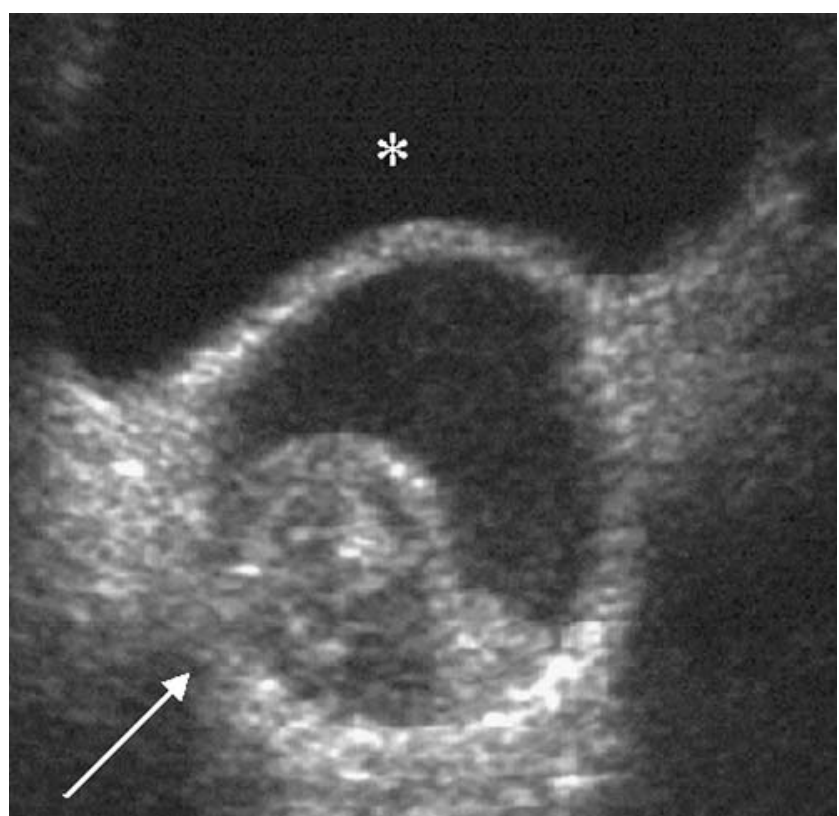

Fig. 14 Mullerian duct cyst. Transverse sonographic image of the bladder in this 15 -year-old boy with recurrent epididymitis demonstrates a cystic mass with internal debris (arrow) posterior to the bladder (asterisk)

its derivation from the Mullerian duct or urogenital sinus [23] or secondary to an error in the production or sensitivity to Mullerian regression factor [25]. Unlike normal prostatic utricles, enlarged prostatic utricles are lined by squamous epithelium. Patients present with urinary tract infection, epididymitis, and postvoid dribbling [23-26]. Diagnosis is made by VCUG. During voiding, filling of a structure arising from the dorsal aspect of the prostatic urethra is seen (Fig. 13). Retrograde urethrography is also diagnostic. In some cases, urethroscopy demonstrates absence of the verumontanum [23].

Enlarged prostatic utricles are classified according to a grading system. In grade 0 , the opening is located in the prostatic urethra but the utricle does not extend over the verumontanum. In grade I the utricle is larger but does not extend to the bladder neck. In grade II, it extends over the bladder neck, and in grade III, the opening of the utricle opens into the bulbous urethra rather than the prostatic urethra [23]. Enlarged prostatic utricles are often seen in patients with intersex, hypospadias (11-14\%), and cryptorchidism. There is a direct relationship between the degree of hypospadias and utricular size [25].

In contrast to enlarged prostatic utricle, Mullerian duct cysts are acquired abnormalities. They present later in life, are not associated with abnormal genitalia and do not communicate with the urethra. Histologically, they are lined by columnar or cuboidal epithelium identical to that of a normal prostatic utricle. Kato et al. [23, 24] have proposed that Mullerian duct cysts develop at a later stage than enlarged prostatic utricles, secondary to narrowing or obstruction of the communication between the normal utricle and the urethra. Patients present with an incidental rectal mass, constipation, urinary retention, hematuria or obstructive azospermia [23-26]. On US, CT or MRI a cystic mass is identified dorsal to the prostatic urethra (Fig. 14). This may contain debris. VCUG is not helpful, since these cysts do not communicate with the urethra. Surgical excision is curative. Of note, there is a 3\% incidence of malignancy in Mullerian duct cysts, most commonly occurring in the fourth decade [25].

\section{Cowper's syringocele}

Cowper's glands are small paired glands located dorsal to and on either side of the membranous urethra. They secrete a mucous substance during ejaculation that acts as a lubricant. The main duct draining Cowper's glands drain below the urogenital diaphragm into the ventral aspect of the bulbous urethra $[27,28]$. During VCUG, the main duct and Cowper's glands can fill with contrast material and appear as a tubular channel paralleling the ventral aspect of the undersurface of the bulbous membranous urethra and ending at the urogenital diaphragm (Fig. 15) [29]. This finding is usually of no clinical significance.

Cowper's syringocele, a rare anomaly, occurs when there is dilatation of the main draining duct. Maizels et al. [30] described four types of Cowper's syringocele: simple syringocele, in which there is reflux into a minimally dilated duct; imperforate syringocele, in which the orifice draining the dilated duct is closed and there is cystic dilatation of the distal duct at the level of the bulbourethra;

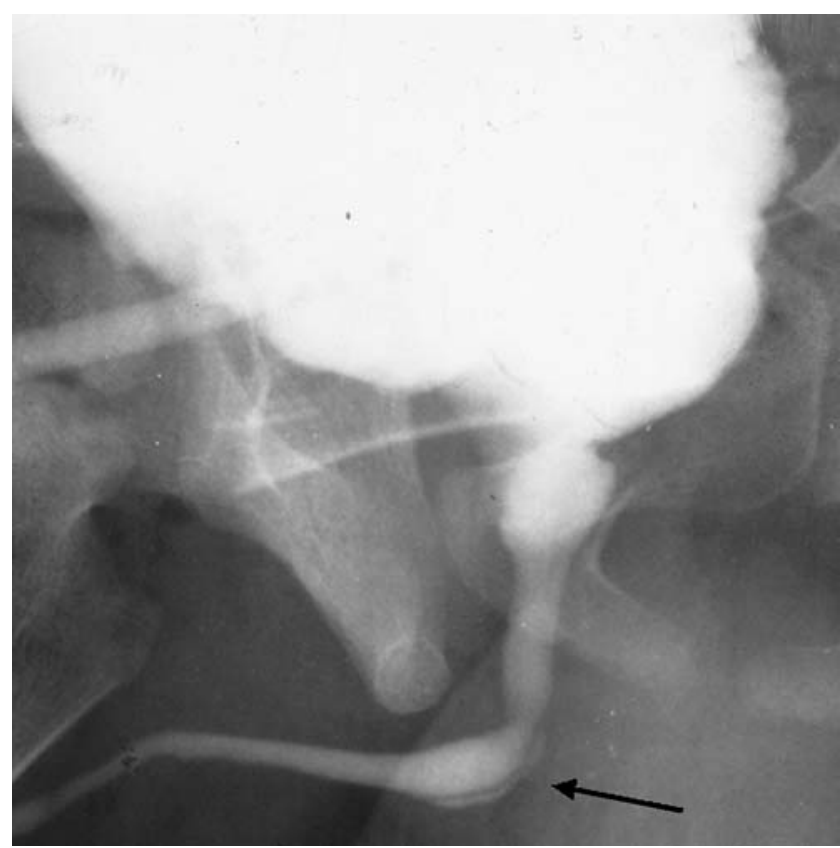

Fig. 15 Cowper's gland. During voiding there is filling of a structure at the ventral aspect of the bulbourethra (arrow) 


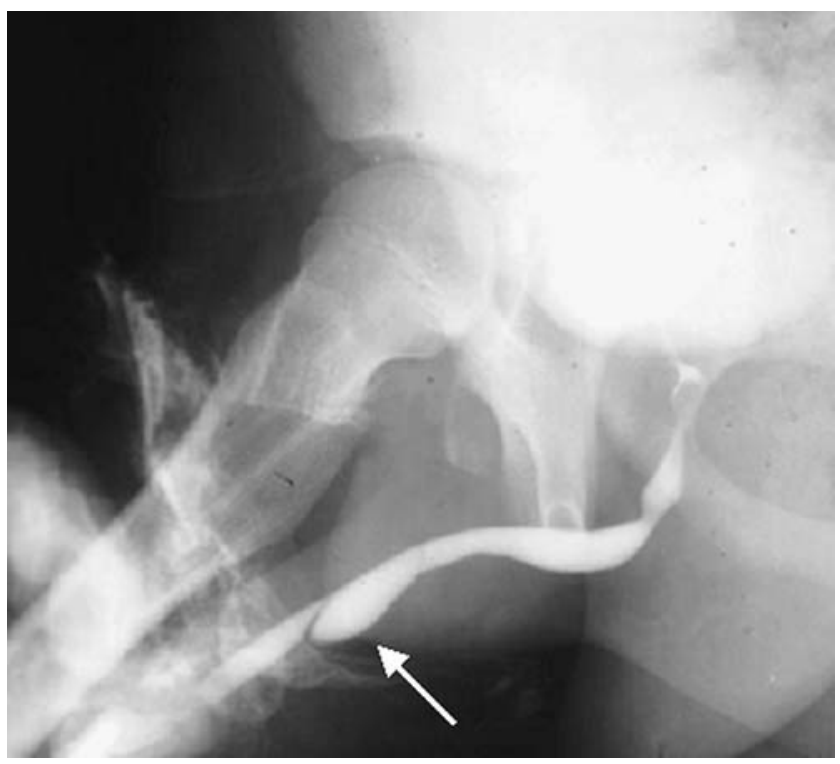

Fig. 16 Anterior urethral diverticulum. Arrow points to a diverticulum arising from and communicating with the ventral aspect of the urethra

perforate syringocele, in which the orifice draining the duct is patulous and there is free reflux into the duct resembling a diverticulum; and ruptured syringocele, in which the distal portion of the duct is dilated but is not in communication with the more proximal portion of the main duct [30]. Cowper's syringocele can also be classified as open or closed, open if it communicates with the urethra and closed if it does not [31].

Clinically, patients present with frequency, urgency, dysuria, post-void incontinence, hematuria or urinary tract infection. Diagnosis is made by VCUG, retrograde urethrography or urethrocystoscopy. Treatment requires marsupialization of the syringocele.

\section{Anterior urethral valves and diverticula}

Anterior urethral valves and diverticula are rare. Most anterior valves (40\%) are located in the bulbous urethra, but they can also be located at the penoscrotal junction (30\%) and penile urethra (30\%) [32]. They are composed of folds located on the ventral aspect of the urethra that rise during voiding, resulting in urethral obstruction [33]. Anterior urethral diverticula communicate with the urethra and are found on the ventral aspect of the urethra between the bulbous and mid-penile urethra [32].

Although many authors distinguish between anterior urethral valves and diverticula, others consider them the same entity. It has been proposed that valves cause proximal urethral dilatation with the formation of a saccular diverticulum [32]. Conversely, progressive enlargement of a diverticulum can result in a distal valve-like flap. Embryologic theories of anterior urethral diverticula formation include a developmental defect in the corpus spongiosum leading to formation of a diverticulum, cystic dilatation of urethral glands, and sequestration of an epithelial rest [33]. McLellan et al. [28] have demonstrated connections between an anterior urethral diverticula and cowperian ducts, proposing that anterior urethral diverticula and valves arise from the anterior lip of a ruptured cowperian duct syringocele.

Clinical presentation depends on the patient's age and the degree of urethral obstruction and includes difficulty voiding, incontinence and recurrent urinary tract infections. VCUG is diagnostic (Fig. 16). Some authors describe a difference in appearance between anterior diverticula and valves; in valves, the urethral dilatation forms an obtuse angle with the ventral floor of the urethra, while in a urethral diverticulum, the angle is acute [31]. Vesicoureteral reflux can be found in up to one-third of patients with anterior urethral valves and $20 \%$ of patients with diverticula [32]. Sonography has also been used for diagnosis [34]. Stone formation within a diverticulum has been reported [35]. Treatment consists of transurethral valve ablation or, in the case of diverticula, transurethral or open diverticulectomy and urethroplasty [32].

Anterior urethral valves occurring in the fossa navicularis, the most distal aspect of the urethra, are referred to as valves of Guerin. These are described as a septum partially separating the lacuna magna (a widening at the dorsal aspect of the distal urethra at the glans penis) from the

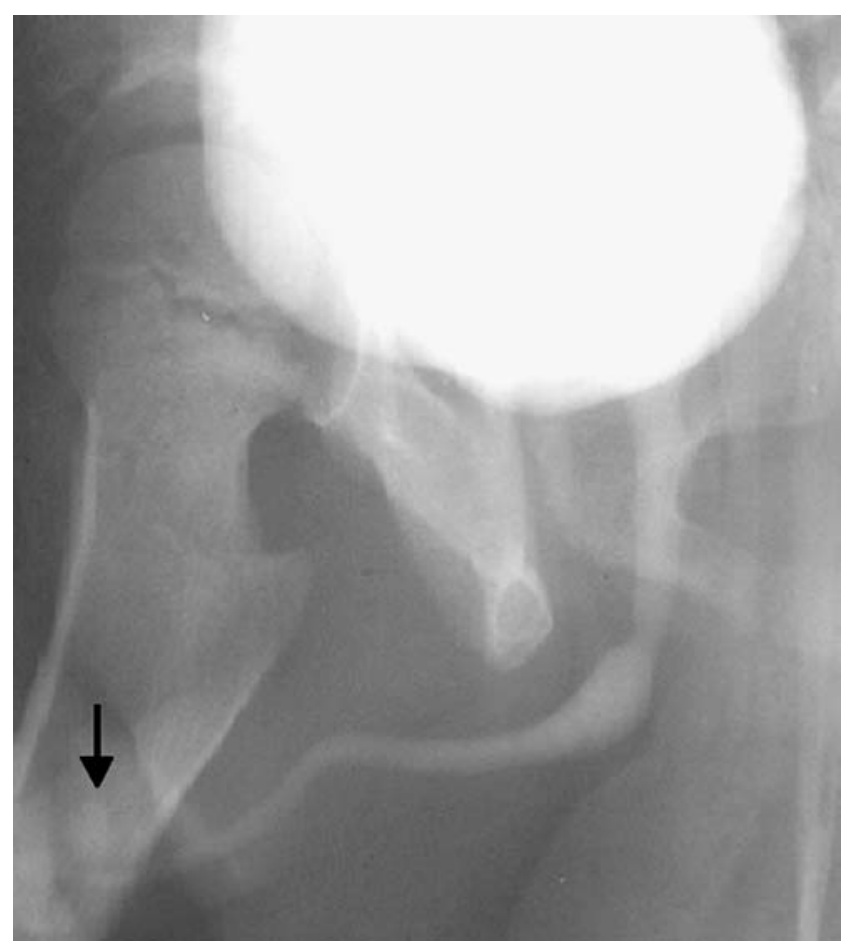

Fig. 17 Valves of Guerin. A small contrast-filled diverticulum (arrow) is present, arising from the dorsal aspect of the glans urethra. There is no urethral obstruction 


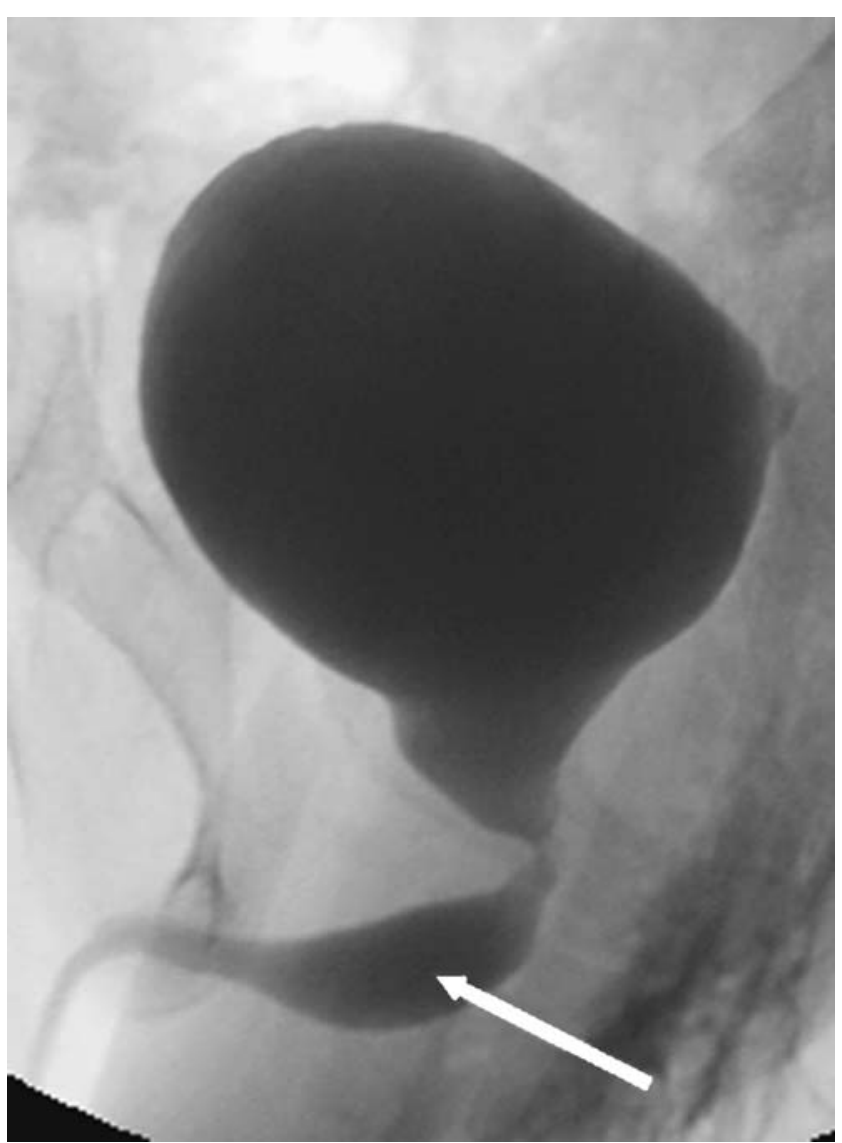

Fig. 18 Megalourethra. Single view from a VCUG in a boy with partial sacral agenesis demonstrates focal dilatation of the urethra (arrow). Note the wide bladder neck

urethra. Valves of Guerin might have a different embryologic basis than other types of anterior urethral valves. Some propose a failure of alignment between the glans urethra and penile urethra while others believe they represent an anatomic variant, as many patients are asymptomatic [36]. Valves of Guerin have been associated with urethral bleeding. VCUG is diagnostic and will demonstrate a small collection of contrast material at the dorsal aspect of the distal urethra (Fig. 17). Marsupialization of the valve into the urethral lumen is the treatment of choice [37].

\section{Megalourethra}

Megalourethra is caused by defective formation of the corpus spongiosum and corpora cavernosa secondary to a mesodermal defect. There are two types of megalourethra: (1) scaphoid, in which there is ventral urethral dilatation and hypoplasia of the corpus spongiosum, and (2) fusiform, in which there is circumferential urethral dilatation and hypoplasia of the corpus spongiosa and corpora cavernosa. Megalourethra is often associated with other congenital abnormalities including cryptorchidism, renal agenesis, hypospadias, primary megaureter, PBS, VACTERL complex [38] and severe gastrointestinal anomalies [39]. These patients have a functional rather than anatomic urethral obstruction, causing stasis and back pressure into the upper urinary tracts. Diagnosis is by VCUG (Fig. 18). Reconstructive surgery is required.

\section{Urethral duplication}

Urethral duplication is a rare anomaly frequently seen in association with other anomalies including hypospadias, epispadias, cleft lip and palate, congenital heart disease, tracheoesophageal fistula, imperforate anus and musculoskeletal anomalies [40].

Duplication commonly occurs along the sagittal plane. The ventral urethra is the more functional urethra and contains the verumontanum and sphincters [40]. When urethral duplication is present along the coronal plane, bladder duplication is always present [41].
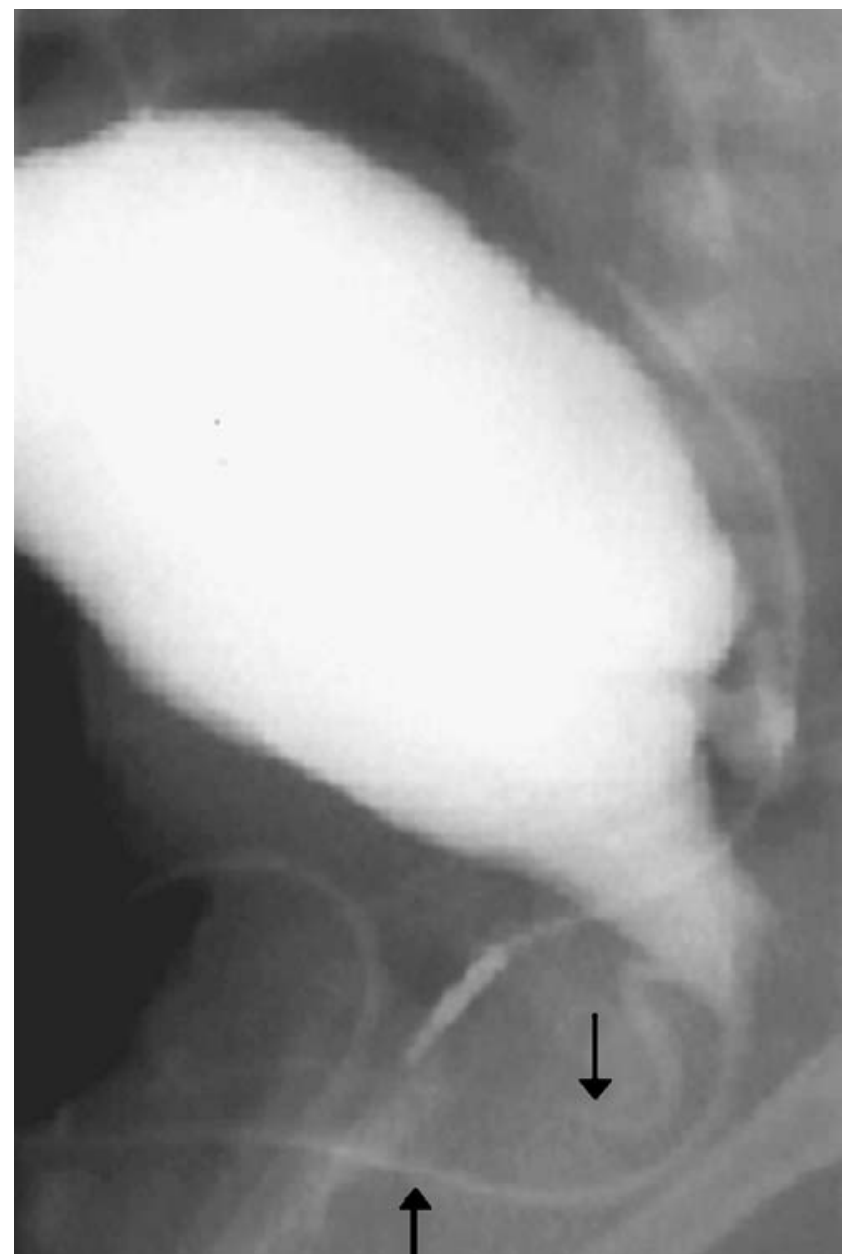

Fig. 19 Complete urethral duplication (type II). Image from a voiding cystourethrogram demonstrates contrast agent filling a dorsal and ventral urethra (arrows). Vesicoureteral reflux is present 
Urethral duplication can be classified into three types using Effmann's classification [42]. In type I, there is partial duplication of the urethra. In type II, there is complete duplication of the urethra. Type II urethral duplication can be subclassified as IIA1 if both urethras arise from separate bladder necks, type IIA2 if one channel arises from the other, and type IIB if there is duplication with one meatus. IIA2 Y-duplication occurs when one urethra arising from the bladder neck or posterior urethra opens to the perineum. This type of urethral duplication often coexists with stenosis of the anterior portion of the normally positioned urethra [43] and other severe congenital anomalies [44]. Type III urethral duplication consists of complete duplication of the urethra and bladder.

Embryologically, urethral duplication can be caused by abnormal Mullerian duct termination and growth arrest of the urogenital sinus [40] or misalignment of the termination of the cloacal membrane with the genital tubercle [41].

Depending on the type of duplication, patients might be asymptomatic. Symptoms include urinary tract infection, epididymitis, and incontinence [43]. Diagnosis can be made by VCUG or retrograde urethrography (Figs. 19 and 20). Urodynamic studies are helpful to confirm the position of the functional urethra in order to distinguish it from congenital urethroperineal fistula (see below) [44]. Onethird of patients have associated vesicoureteral reflux [41].

\section{Congenital urethroperineal fistula}

Although congenital urethroperineal fistula (CUF) resembles Y-type urethral duplication, it should be considered a

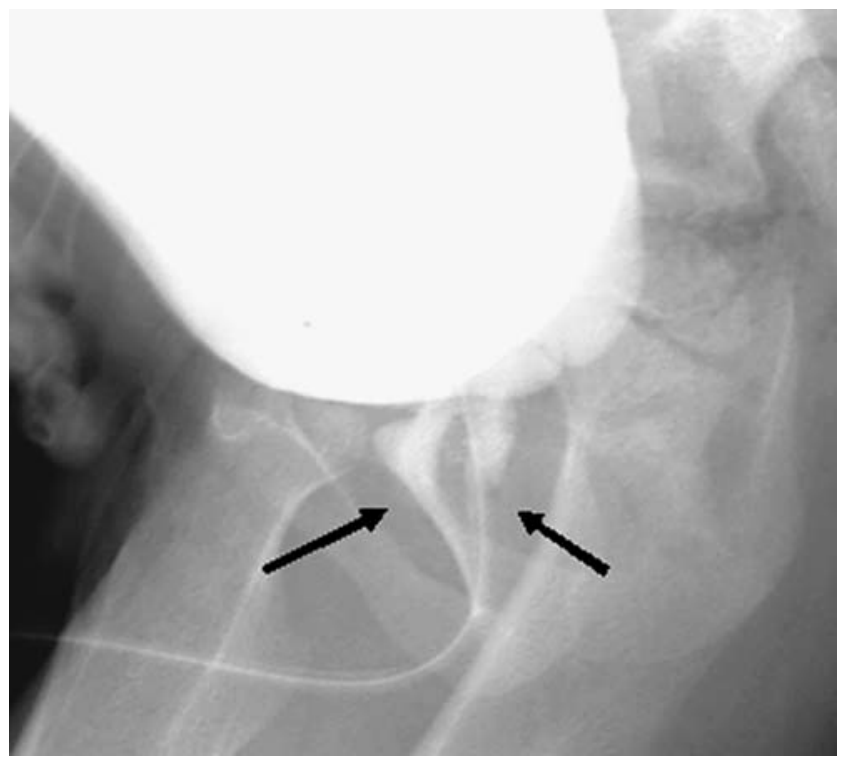

Fig. 20 Partial urethral duplication (type I). There is partial duplication of the urethra in this patient with a history of hypospadias repair. The two channels (arrows) join to a single channel, which is demarcated by the catheter

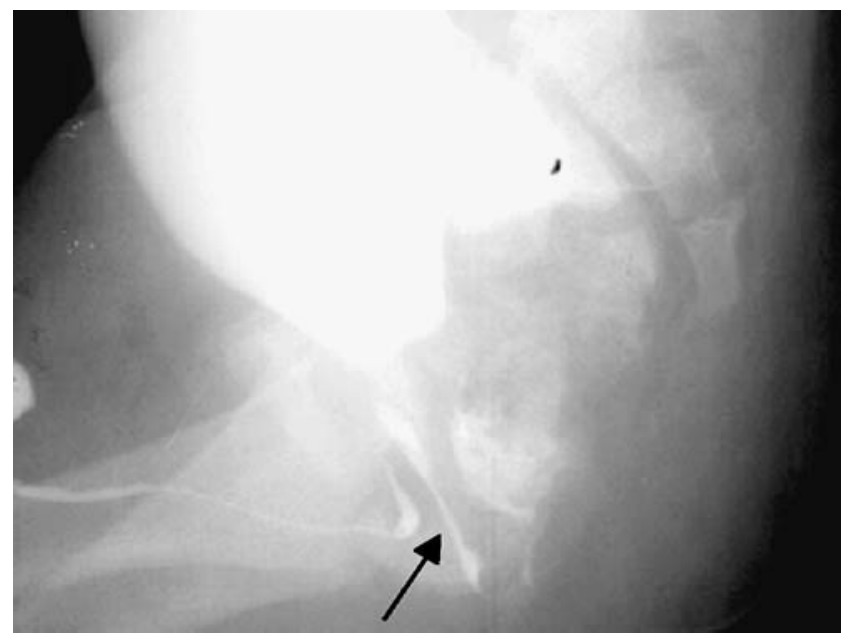

Fig. 21 Anorectal malformation. Image from a VCUG demonstrates an anourethral fistula (arrow) in a newborn. This is also referred to as an H-type fistula because of its configuration

separate entity. In Y-type urethral duplication the ventral urethra opens to the perineum and, as in all urethral duplications, is the functional urethra. In contrast, in CUF, the dorsal urethra is the functional urethra and the ventral urethra (fistula) is hypoplastic [41, 45]. The differentiation between Y-type duplication and CUF is particularly important in the surgical management of these patients. In Y-duplication the functional ventral channel should not be

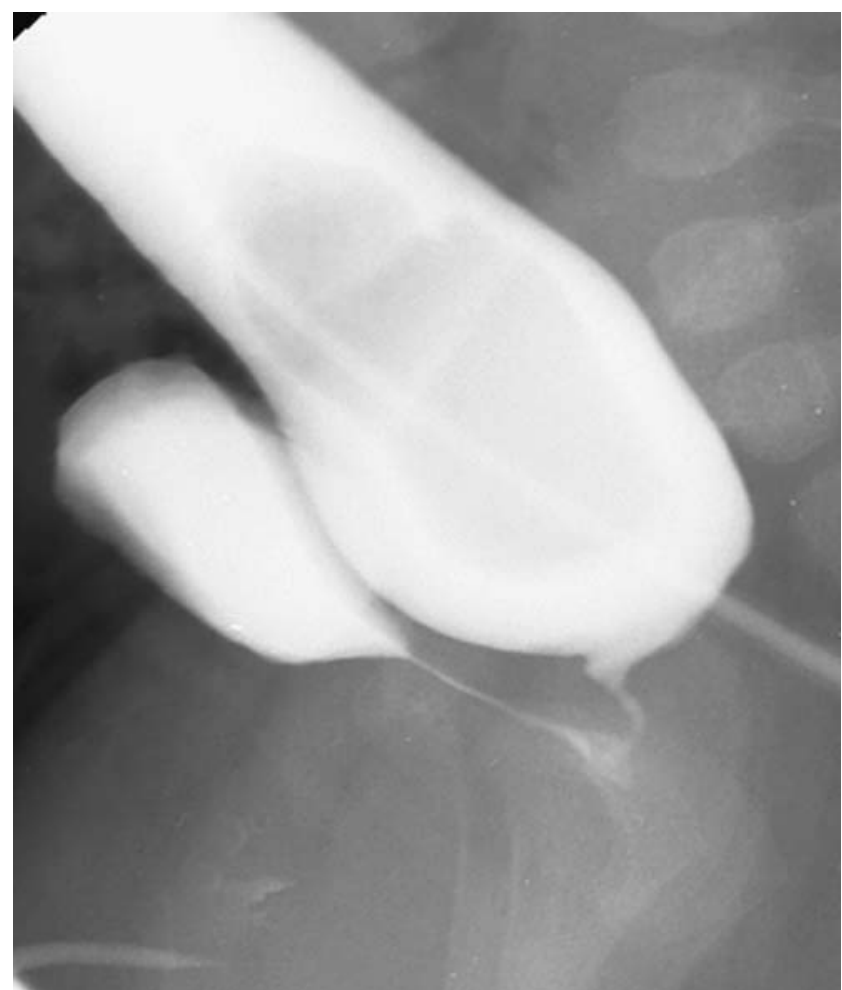

Fig. 22 Anorectal malformation. Distal loop study in an infant with a high imperforate anus demonstrates a fistula extending from the rectum to the posterior urethra 
resected, while in the CUF resection of the ventral channel is curative [45].

The embryology of CUF is not clear. Diagnosis is made by retrograde urethrography or VCUG to determine the dominant urethra. In the case of congenital urethroperineal fistula, voiding will be predominantly through the dorsal urethra. Urodynamics is important to determine the position of the external urethral sphincter [39].

\section{Anorectal malformations}

Congenital anorectal malformation represents a complicated spectrum of anomalies that range from anal stenosis to imperforate anus with communication with the urogenital system [46]. In males, the anomaly is characterized by gastrointestinal anomalies, imperforate anus and frequently other congenital anomalies including tracheoesophageal fistula, heart disease, limb anomalies and radial and renal abnormalities (VACTERL complex) [47]. The malformation can be classified as low or high/intermediate. Fistulous communications between the blind-ending rectum and the urinary tract are more common in males with high/ intermediate anomalies. Rectobulbocutaneous fistulous tracts have also been described in which a fistula arises from the rectum, communicates with the bulbous urethra at its mid-portion and continues ventrally to terminate at the scrotum wall $[48,49]$. A concurrent rectourethral fistula to the posterior urethra or, less commonly, the bladder, has been described in $28 \%$ of patients of imperforate anus [50] and there is a high incidence of other urethral anomalies as well $[39,40]$.

Embryologically the normal sequence of cloacal division by the urorectal septum into the urogenital sinus and rectum is disrupted. Preexisting fusion of mesoderm at the dorsal aspect of the cloacal folds might be present, which prevents normal caudal descent of the urogenital septum and results in a urorectal septal defect. Recent reports describe a possible genetic link between abnormalities of the Sonic Hedgehog gene (Shh) and midline developmental abnormalities such as those seen with the VATERL association [40, 47, 51].

Diagnosis is made by VCUG or distal loop study following colostomy (Figs. 21 and 22).

\section{Conclusion}

The development of the male urethra is complex. Although understanding its embryology can help explain certain anomalies, there are others in which the embryologic defect has not been elucidated. Imaging, including VCUG and retrograde urethrography, is helpful in defining the anatomy and identifying associated findings.

\section{References}

1. Krishan A, de Souza A, Konijeti R et al (2006) The anatomy and embryology of posterior urethral valves. J Urol 175:1214-1220

2. Hynes PJ, Fraher JP (2004) The development of the male genitourinary system I: the origin of the urorectal septum and the formation of the perineum. Br J Plast Surg 57:27-36

3. Hynes PJ, Fraher JP (2004) The development of the male genitourinary system II: the origin and formation of the urethral plate. Br J Plast Surg 57:112-121

4. Hynes PJ, Fraher JP (2004) The development of the male genitourinary system III: the formation of the spongiose and glandar urethra. Br J Plast Surg 57:203-214

5. Gray H (1973) The urogenital system. In: Goss CM (ed) Gray's anatomy of the human body. Lea and Febiger, Philadelphia, pp 1296-1297

6. Dewan P, Pillay S, Kaye K (1997) Correlation of the endoscopic and radiological anatomy of congenital obstruction of the posterior urethra and the external sphincter. Br J Urol 79:790-796

7. Manzoni C, Valentini AL (2002) Posterior urethral valves. Rays 27:131-134

8. Kumar A, Bajpai M, Gupta AK (2005) Double urethral obstruction in a neonate: a case report. Eur J Pediatr Surg 15:449-451

9. Robertson WB, Hayes JA (1969) Congenital diaphragmatic obstruction of the male posterior urethra. J Urol 93:592-598

10. Dewan PA, Keenan RJ, Morris LL et al (1994) Congenital urethral obstruction: Cobb's collar or prolapsed congenital obstructive posterior urethral membrane (COPUM). Br J Urol 73:91-95

11. El-Ghoneimi A, Desgrippes A, Luton D et al (1999) Outcome of posterior urethral valves: to what extent is it improved by prenatal diagnosis? J Urol 162:849-853

12. Holmes N, Harrison MR, Baskin LS (2001) Fetal surgery for posterior urethral valves: long-term postnatal outcomes. Pediatrics 108:E7

13. Levin TL, Abramson SJ, Burbige K et al (1991) Salt losing nephropathy simulating congenital adrenal hyperplasia in infants with obstructive uropathy and/or vesicoureteral reflux - value of ultrasonography in diagnosis. Pediatr Radiol 21:413-415

14. Lopez Pereira P, Espinosa L, Martinez Urrutina MJ et al (2003) Posterior urethral valves: prognostic factors. BJU Int 91:687-690

15. Cohen HL, Susman M, Haller JO et al (1994) Posterior urethral valve: transperineal US for imaging and diagnosis in male infants. Radiology 192:261-264

16. Cremin BJ (1975) Urinary ascites and obstructive uropathy. Br J Radiol 48:113-117

17. Goulding FJ, Garrett RA (1978) Twenty-five-year experience with prune belly syndrome. Urology 12:329-332

18. Siegel MJ, Herman TE (1999) Special imaging casebook. Prunebelly syndrome with urachal diverticular calcification, posterior urethral valves, and patent utricle. J Perinatol 19:610-612

19. Lendvay TS, Smith EA, Kirsch AJ et al (2002) Congenital urethral stricture. J Urol 168:1156-1157

20. Sugimoto M, Kakehi Y, Yamashita M et al (2005) Ten cases of congenital urethral stricture in childhood with enuresis. Int J Urol $12: 558-562$

21. Staddas JO (1973) Pedunculated polyp of the posterior urethra in children causing reflux and hydronephrosis. J Pediatr Surg 8:517-521

22. Aragona F, Di Tonno F, Tuccitto G et al (1988) Congenital polyp of the prostatic urethra: report on 2 cases. Urol Int 43:113-117

23. Kato H, Masayoshi H, Furuya S et al (2005) Anatomical and histological studies of so-called Mullerian duct cyst. Int J Urol 12:465-468

24. Kato H, Komiyama I, Maejima T et al (2002) Histopathological study of the Mullerian duct remnant: clarification of disease categories and terminology. J Urol 167:133-136 
25. Krstic Z, Smoljanic Z, Micovic Z et al (2001) Surgical treatment of Mullerian duct remnants. J Pediatr Surg 36:870-876

26. Schuhrke T, Kaplan G (1978) Prostatic utricle cysts (Mullerian duct cysts). J Urol 119:765-767

27. Zugor V, Schrott K, Schott GE (2006) Cowper's syringocele - a rare malformation of the male urethra. Urol Int 76:182-185

28. McLellan DL, Gaston MV, Diamond DA et al (2004) Anterior urethral valves and diverticula in children: a result of ruptured Cowper's duct cyst? BJU Int 94:375-378

29. Karnak I, Senocak ME, Buyukpamukcu N et al (1997) Rare congenital abnormalities of the anterior urethra. Pediatr Surg Int 12:407-409

30. Maizels M, Stephens FD, Lowell RK et al (1983) Cowper's syringocele: a classification of dilatations of Cowper's gland duct based upon clinical characteristics in 8 boys. J Urol 129:111-114

31. Bevers RFM, Abbekerk EM, Boon TA (2000) Cowper's syringocele: symptoms, classification and treatment of an unappreciated problem. J Urol 163:782-784

32. Zia-ul-Miraj M (2000) Anterior urethral valves: a rare cause of infravesical obstruction in children. J Pediatr Surg 35:556-558

33. Paulhac P, Lourcade L, Lesaux N et al (2003) Anterior urethral valves and diverticula. BJU Int 92:506-509

34. Goyal M, Sharma R, Gupta DK et al (1996) Congenital anterior urethral diverticulum: sonographic diagnosis. J Clin Ultrasound 24:543-544

35. Karanth KS, Yeluri SV, Desai RM et al (2003) Congenital anterior urethral diverticulum with stone: a unique presentation. Urology 61:837

36. Scherz HC, Kaplan GW, Packer MG (1987) Anterior urethral valves in the fossa navicularis. J Urol 138:1211-1213

37. Friedman RM, King LR (1993) Valve of Guerin as a cause of dysuria and hematuria in young boys: presentation and difficulties in diagnosis. J Urol 150:159-161

38. Vaghefi H, Simmons MN, Hsia MH et al (2006) Two extremes of the megalourethra spectrum. Urol 67:614-616
39. Wakhlu AK, Wakhlu A, Tandon RK et al (1996) Congenital megalourethra. J Pediatr Surg 31:441-443

40. Haleblian G, Kraklau D, Wilcox D et al (2006) Y-type urethral duplication in the male. BJU Int 97:597-602

41. Salle JLP, Sibai H, Rosenstein D et al (2000) Urethral duplication in the male: review of 16 cases. J Urol 163:1936-1940

42. Effmann EL, Lebowitz RL, Colodny AH (1976) Duplication of the urethra. Radiology 119:179-185

43. Okeke LI, Aisuodionoe-Shadrach O, Adekanye A (2006) Urethral duplication with a perineal opening in a four-year-old boy. J Natl Med Assoc 98:284-286

44. Wagner JR, Carr MC, Bauer SB et al (1996) Congenital posterior urethral perineal fistulae: a unique form of urethral duplication. Urology 48:277-280

45. Bates DG, Lebowitz R (1995) Congenital urethroperineal fistula. Radiology 194:501-504

46. van der Putte SCJ (2006) Anal and ano-urogenital malformations: a histopathological study of "imperforate anus" with a reconstruction of the pathogenesis. Pediatr Dev Pathol 9:280-296

47. Mauch TJ, Albertine KH (2002) Urorectal septum malformation sequence: insights into pathogenesis. Anat Rec 268:405-410

48. Currarino G (1994) Imperforate anus associated with a rectobulbar-cutaneous fistula. J Pediatr Surg 29:102-105

49. Kumar V, Rao PL, Vepakomma D (2005) Low anorectal malformation associated with 'ano-urethro-cutaneous' fistula. Pediatr Surg Int 21:829-830

50. Endo M, Hayashi A, Ishihara M et al (1999) Analysis of 1,992 patients with anorectal malformations over the past two decades in Japan. Steering Committee of Japanese Study Group of Anorectal Anomalies. J Pediatr Surg 34:435-441

51. Fernbach SK (1991) Urethral abnormalities in male neonates with VATER association. AJR 156:137-140 